\title{
10. Türkçe Sözlük’te İngilizceden alıntı sözlükbirimlerin tanım görünümleri
}

\section{Mustafa Samet KUMANLI}

APA: Kumanlı, M. S. (2021). Türkçe Sözlük’te İngilizceden alıntı sözlükbirimlerin tanım görünümleri. RumeliDE Dil ve Edebiyat Araştırmaları Dergisi, (24), 158-173. DOI: 10.29000/rumelide.990117.

$\ddot{O} \mathbf{z}$

Türkçe, konuşur sayısı fazla olan dillerdendir. Tarihsel süreç içerisinde kendine özgü dilbilgisi ve söz varlığı özelliklerini beraberinde getirmiştir. Dillerin en büyük özelliklerinden biri de kültürel etkileşim sonucunda farklı yollarla birbirlerinden sözcük ödünçlemeleridir. Türkçe de doğal olarak, tarih boyunca etkileşimde bulunduğu dillerle sözcük alışverişinde bulunmuştur. Kültürel etkileşimin boyutları zamana ve mekâna göre değişiklik gösterdiği için kültürel etkileşimde bulunulan diller de zamanla değişmiştir. Örneğin Eski Türkçe döneminde çoğu kez Moğolca ve Çinceden ödünçlemeler yapılıyorken İslam dininin kabulü ile birlikte Arapça ve Farsçadan birçok sözcük ödünçlemesi yapılmıştır. Arapça ve Farsça ödünçlemeler Osmanlı Türkçesi döneminde yoğunluğunu artırmıştır. Osmanlı Türkçesinin son dönemlerinden itibaren ise kültürel, siyasal ve teknolojik gelişmeler ile Batı toplumuyla kurulan ilişkilerin artması dolayısıyla özellikle Fransızcadan birçok sözcük ödünçlenmiştir. Cumhuriyet dönemi ile birlikte Fransızca sözcüklerin yanında diğer Batı dillerinden özellikle de İkinci Dünya Savaşı’nın ardından İngilizceden ödünçlenen sözcüklerin sayısında artış görülmüştür. Söz konusu sözcüklerin kullanım sıklığının artması ile birlikte bu sözcüklere sözlüklerde yer verilme gerekliliği ortaya çıkmıştır. Türkiye Türkçesinin genel sözlüklerinden biri olan TDK Türkçe Sözlük (TS) çok sayıda alıntı sözlükbirime sahiptir. Bu çalışmada, TS'de yer alan İngilizceden ödünçlenmiş sözlükbirimlerin tanımlanması üzerinde durularak, TS'deki tanım görünümlerini irdelenecektir. Çalışmada, Türk sözlükbiliminde sorunlu noktalardan olan tanımlama ve alıntı sözlükbirimlerin tanımlanması konularına TS, WORDNET ve Merriam Webster Sözlüğündeki tanımların karşılaştırılması ile yaklaşılmış ve belirlenen sorunlara çözüm önerileri sunulmuştur.

Anahtar kelimeler: Türkçe Sözlük, sözlüksel tanım, sözlükbilim, alıntı sözlükbirimler, İngilizce alıntılar

\section{Definition methods of lexemes borrowed from English in Turkish Dictionary}

\begin{abstract}
Turkish is one of the most widely spoken languages in the world, and it has brought its own rules and accumulations based on grammar and vocabulary throughout the historical process. One of the most important features of languages is the borrowing of words from each other in different ways as a result of cultural interaction. Turkish has also naturally exchanged words with the languages in which it has interacted with throughout history. Since the dimensions of cultural interaction vary according to time and place, the languages interacted with culturally have also changed over time. For example, in the Old Turkish period, while most of the borrowings were made from Mongolian and Chinese, many words were borrowed from Arabic and Persian with the adoption of the religion of Islam. While
\end{abstract}

Dr., Bağımsız Araştırmacı (Ankara, Türkiye), m.sametkumanli@outlook.com, ORCID ID: oooo-ooo1-8262-8384 [Araştırma makalesi, Makale kayıt tarihi: 19.07.2021-kabul tarihi: 20.09.2021; DOI: 10.29000/rumelide.990117

Adres | Address

RumeliDE Dil ve Edebiyat Araşturmaları Dergisi Osmanağa Mahallesi, Mürver Çiçeği Sokak, No:14/8 Kadıköy - ISTANBUL / TÜRKIYE 34714 e-posta: editor@rumelide.com

RumeliDE Journal of Language and Literature Studies Osmanağa Mahallesi, Mürver Çiçeği Sokak, No:14/8

Kadıköy - ISTANBUL / TURKEY 34714 tel: +90 $5057958124,+902167730616$

e-mail: editor@rumelide.com

phone: +90 $5057958124,+902167730616$ 
Arabic and Persian borrowings increased their intensity during the Ottoman Turkish period, many words were borrowed from French especially due to cultural, political and technological developments and increased relations with Western society since the end of the period. The TDK Turkish Dictionary (TD), which is the official dictionary of Turkish, has the characteristic of being the most important resource that should be examined in this regard. In this study, definition and definition of quoted lexicons, which are problematic points in Turkish lexicography, are approached by comparing the definitions in TS, WORDNET and Merriam Webster Dictionary and solutions to the identified problems are presented.

Keywords: Turkish Dictionary, lexical definition, lexicography, borrowings, English borrowings

\section{Giriş}

Sözlükbilim (lexicography); anlambilim ve dilbilim ile bağlantılı ancak bağımsız bir alan olarak son yıllarda özellikle teorik alanda yapılan çalışmalarla gelişim göstermektedir. Svénsen sözlükbilimi şu şekilde tanımlamıştır: "Bir veya birden fazla dilde, sözcük, sözcükbirim, sözcük birleştirmeleri gibi birçok leksikal birimi inceleyerek derlemeyi, seçmeyi ve analiz ederek betimlemeyi içeren bir aktivitedir" (Svensén, 2009: 2). Svensén’in tanımı incelendiğinde sözlükbilimi; sözlüğün dış yapısı ile ilgili derleme, seçme faaliyetleri ve analiz ederek betimleme gibi iç yapıyı ilgilendiren tanım (definition) konusunu da içeren bir bütünlük olarak ifade ettiği görülür. Hartmann'ın sözlükbilim tanımı ise şu şekildedir: "Sözlükbilim, uygulama ve teori olmak üzere iki boyuta sahiptir. Birçok genel ve tarihi İngilizce sözlükte sözlükbilim uygulama yönüyle tanımlanır. Ancak sözlükbilim, sözlük yapımı (uygulamalı alan) ve sözlük araştırmaları (sözlük teorisi) ile birlikte gelişmekte olan bir sahadır” (Hartmann, 2001: 4). Tanımda, sözlük yapımı ve sözlük araştırmaları olmak üzere iki alt başlık verilmiş ve sözlükbilimin iki ayrı yönüne vurgu yapılmıştır. Çalışmada alıntı sözcükler üzerinden ele alacağımız tanım (definition) konusu, sözlükbilimin kuramsal ve uygulamalı alanlarının kilit noktasını oluşturan ve kuramsal alanın uygulamaya en çok katkı sağladığı alan olarak öne çıkmaktadır.

Sözlükbilimin en önemli konularından biri, sözlükbirimlerin nasıl tanımlanacağı konusudur. Tanımlar, tanımlanacak sözlükbirimin gerektirdiği biçimde amaç bakımından tanım türlerine ayrılırlar. Dolayısıyla; tanım türleri, tanımda neyin tanımlandığı ile ilgilidir. Tanım yöntemleri ise tanımda yapılmaya çalışılan, yani tanımın amacının gerçekleştirilebilmesi için hangi yöntemin benimseneceğini ifade eder. Farklı tanımlar, farklı amaçlara sahip olabileceği için bu amaçlara farklı yöntemlerle ulaşlabilir. Örneğin; "adsal tanım ifadesi, bit tanım türünü ifade ederken; gösterimsel tanım ifadesi, işaretleme ve fiziksel görüntü kullanılarak yapılan bir tanım yöntemini ifade eder" (Robinson, 1962: 15). Sözlüklere sözlükbirim seçimi (lemma selection) ile birlikte sözlüklerde yer alan sözlükbirimlerin tanımlarında kullanılan yöntemler (definition methods) sözlükbirimin temel çalışma alanlarını oluşturur.

Türkçede alıntı sözlükbirimler üzerine yapılan çalışmalar ise nicelik bakımından sınırlıdır. Yapılan çalışmalar genellikle bu alıntıların kaynak dilleri üzerine veya TS'de yaşadıkları ses olaylarına ilişkindir. Sözlüklerde yer alan alıntı sözlükbirimler, dilde belirli bir kavram alanını karşılayan göstergelerdir. Dolayısıyla alıntı sözlükbirimlerin anlam bakımından incelenebilmesi için sözlüklerde yapılan tanımlarında kullanılan yöntemlerin irdelenmesi gerekmektedir.

"Bir dilin, başta leksikolojik olmak üzere, morfolojik ve söz dizimsel özellikleri ortaya çıkarılırken alıntı ögelere dikkat edilip bunların değerlendirilmesi şarttır. Alıntı ögelerin yeterince belirlenip ortaya

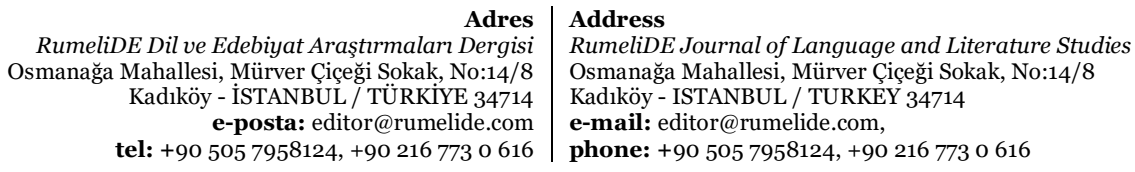


konulmaması söz konusu çalışmaları eksik bırakacaktır” (Durmuş, 2004, s. 2). Durmuş’un da belirttiği gibi alıntı sözcükler, dâhil oldukları dilde zaman içerisinde yerli sözcüklerin kullanım alanını sınırlayıp anlam alanını genişleterek kullanımda büyük yer elde edebileceği için Türkçe üzerine yapılacak anlamsal çalışmalarda alıntı sözcüklerin ihmal edilmemesi gerekir.

Alıntıların Türkçeye geçişinin ise iki şekilde gerçekleştiği vurgulanmıştır:

Anadolu ve Rumeli'de yerleşen ve dallanan dilimizin Arapça ve Farsçadan kelime alması yazıda sınırsız, fakat konuşmada sınırlı olmuştur. Bunlar çoğu yazıdan, gözle alıntı kelimelerdir. Anadolu dilimizi iki medeniyet diliyle daha temasa getiriyor: Rumca ve İtalyanca. Ancak bunlar yazılarını bilmediğimiz ayrı medeniyet çevresine ait oldukları için bize hemen yalnız konuşmadan, kulakla alıntı yolundan teknik kelimeler vermişlerdir: Temel, takoz, poyraz, firı, kaptan, gümrük, manivela gibi (Banguoğlu, 2000, s. 110).

Alıntı sözcüklerin herhangi bir dile girişi çok özel durumlar sonucunda da gerçekleşebilir. Ancak genel anlamda alıntıların alıcı dile geçişindeki nedenleri Buran, "sosyal hayattaki köklü değişiklikler, din ve medeniyet dairesindeki değişiklikler, tercüme faaliyetleri, alfabe değişiklikleri, geri kalmışlık, dil bilinci eksikliği, çok coğrafya değiştirmek, dilin türetme yapısının kısırlığı, bilimsel ve teknolojik yenilikler, özenti kişilerin beğenilme arzusu” şeklinde sıralamıştır (Buran, 2001: 79). TS'de bulunan İngilizceden alıntı sözlükbirimler incelendiğinde ise genellikle bilimsel ve teknolojik yeniliklerle bağlantılı olarak alıntılanmış terim niteliğindeki sözlükbirimler olduğu görülür.

TS, ölçünlü Türkçenin genel sözlüklerinden biri olması sebebiyle sözlükbilimi incelemelerine sıkça konu olmaktadır. Bu çalışmaların büyük bir kısmı Türkçe sözlükbirimler üzerine yapılırken, Türkçenin diğer dillerden ödünçlediği ve TS'de sözlükbirim olarak yer alan sözcükler üzerine karşılaştırmalı çalışmalar yeterli sayıda değildir. Türkçenin söz varlığı genişledikçe, TS’de yabancı dillerden alıntılanan sözlükbirim sayısı da artmaktadır. Türkçenin tarihsel süreci içerisinde en fazla sayıda sözcük Arapça, Fransızca ve Farsçadan ödünçlenmiş olsa da özellikle son yıllarda Türkiye Türkçesinin söz varlığında İngilizce sözcüklerin sayısı giderek artmaktadır. TS’nin 11. baskısındaki alıntı sözlükbirimlerin sayısal verilerinin görünümü; Arapça 6.516, Fransızca 5.540, Farsça 1.375, İtalyanca 607, İngilizce 518, Rumca 448, Almanca 105, Latince 68, Rusça 39, Yunanca 37, İspanyolca 31, Ermenice 24, Bulgarca 22, Macarca 15, Japonca 13, Moğolca 12, İbranice 8, Malay dili 2, Portekizce 2, Soğdca 2, Arnavutça 1, Korece 1, Sırpça 1, Slavca 1 biçimindedir (Türkçe Sözlük, 2011, s. 2674). Bu veriler incelendiğinde önceki baskılarla sıralamayı değiştirmeyecek ölçüde farklılıkların olduğu görülmektedir. Bu durumun nedenlerinden biri, Türkçenin söz varlığında yaşanan değişimlerin dışında TS’ye sözlükbirim seçiminde görülen tercihlerdir.

"Alıntı sözlükbirimlerin sayıları konusunda baskılara göre çeşitli değişimler görülmektedir. Bazen aynı sözlüğün farklı baskılarındaki kaynak dilbilgisi dahi değişmektedir. Sözlüklerde madde başı olan alıntı sözlerin kaynak dillerine ilişkin sayısal dalgalanmalar, yalnızca o dillerden yeni sözlerin girmesine ya da bu sözlerin kullanımdan kalkmasına bağlı olmayıp her baskıda pek çok sözün öncekinden başka bir dile ait sayılmasıyla da ilgilidir" (Ergene, 2014, s. 650). Alıntı sözlükbirimlerin sayısal verileri, dilin dış tarihi içerisinde gerçekleşen etkileşimler sonucunda ortaya çıkan sonuçlardır. Çalışmamız kapsamında İngilizceden Türkiye Türkçesine alıntılanmış sözlükbirimlerin tanımlarında kullanılan tanım yöntemleri üzerinde duracă̆ız.

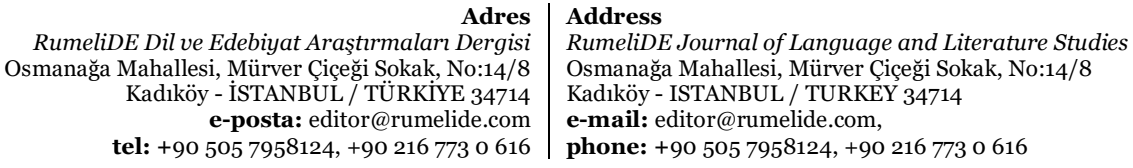

Adres
RumeliDE Dil ve Edebiyat Araştırmaları Dergisi Kadı̈̈y - İT tel: +90 505 7958124, +902167730616 


\section{Türkçe Sözlük’ün İngilizceden alıntı sözcüklerde tanım eğilimleri}

Kültürler arasındaki ilişkiler çeşitli dönemlerde değişiklik gösterdiği gibi bu ilişkilerin kültürün bir parçası olan dile yansıması da kaçınılmaz olmaktadır. Dilin söz varlığında yaşanan bu değişimler ölçünlü dilin sözlükleri tarafından kayda geçirilir. Bu durum, sözlüklerde bulunan sözlükbirim saylarındaki dağılımı etkilemektedir. Son yıllarda TS'de İngilizce kökenli sözlükbirimlerin sayısının artması Türkçenin ödünçleme eğilimindeki değişimi göstermesi bakımından önemlidir.

Aksan; alıntı sözcükleri, "sözcükbilimde alışılmış terimleriyle yerleşmiş yabancı sözcükler ve yerleşmemiş yabancı sözcükler” olarak ikiye ayırmış ve ilk ulamda bulunan sözcüklerin alıcı dilin ses kurallarına uyduğunu ikinci ulamda bulunan sözcüklerin ise orijinal yazımlarını koruduğunu belirtmiştir (Aksan, 2004: 29). Biz de bu bağlamda alıntı sözlükbirimleri yazımı değişenler ve değişmeyenler olmak üzere iki farklı ulamda değerlendireceğiz.

TS’nin 11. baskısında İngilizce kökenli toplam sözlükbirim sayısı 517'dir. Bu sözcüklerden 204'ü Türkçeye yeni girmiş bir diğer deyişle yazımı Türkçede değişmemiş sözlükbirimlerdir. Geriye kalan 313 sözcük ise Türkçeye girişi daha eski tarihlerde gerçekleşen ve Türkçede yazımı değisşen sözlükbirimlerdir. Bu ayrımın yapılmasının amacı, çalışmamızda TS ile WORDNET ve Merriam Webster sözlükleri arasındaki tanımlar karşılaştırmalı olarak incelenirken tanımda yer alan anlamsal farklılıkların da takip edilebilmesidir.

Bu sözcüklerden, orijinal yazımı ile maddebaşı yapılan 204 sözlükbirimin 116'sının tanımında sözlük kullanıcısı, gönderme (cross-reference) uygulanarak $b k$. etiketi ile Türkçede üretilen karşıllğa gönderilmiştir. Örneğin, dribbling sözcüğü için sözcük kullanıcısı, top sürme maddesine gönderilirken; transporter sözlük birimi için de okuyucu, yükçeker sözlükbirimine gönderilmiştir. Geriye kalan 313 sözcük ise Türkçeye girişi daha eski tarihte gerçekleşen ve Türkçede yazımı Türkçeleşmiş sözlükbirimlerdir. $\mathrm{Bu}$ nedenle de tanımlarında herhangi bir maddeye gönderme yapma ihtiyacı duyulmamıştır. Hobi, klip, skeç gibi sözcükler bu tip sözlükbirimlerdir.

TS'de Türkçeye İngilizceden giren sözlükbirimler için İng. etiketi kullanılır ve sözcüklerin tanımı verilirken diğer sözlükbirimlerde olduğu gibi sözcük türü etiketi verilir ardından da İng. etiketi ve sözcügün İngilizcedeki asıl yazımı gösterilir. Son olarak da sözcüğün hangi alana ait olduğunu belirten alan etiketi yer alır. TS’nin alıntı sözlükbirimlerde kullandığı tanım yöntemlerini belirli sözlükbirimler üzerinden incelemek yerinde olacaktır.

TS’de yer alan İngilizceden ödünçlenmiş sten I sözlükbiriminin tanımı şu şekilde yapılmıştır:

sten (I): isim, askerlik, İngilizce, Sten. "Çapı 9 milimetre olan, İngiliz yapısı, hafif, kullanışı kolay bir makineli tüfek"

Sözlükbirimin tanımında, sözcük türü etiketi isim şeklinde verilerek, kullanım alanı da askerlik etiketi ile belirtilmiştir. Sözlükbirimin kaynak dili İngilizce etiketi ile sözlük kullanıcısına sunulmuş ve kaynak dildeki Sten biçimi işaretlenmiştir. Sözcüğün tanımında ise makineli tüfek üst kavramı; çapının genişliği, kimler tarafindan yapıldığı ve kullanım nitelikleri ayırt edici özellik olarak verilerek betimlenmiş ve analitik tanım yöntemi kullanılmıştır. Sözlükbilimin kuramsal yönünün en önemli unsurlarından olan tanımlamanın genel sözlüklerdeki uygulamasının izlenebilmesi için en uygun yöntemlerden biri, sözlükler arasındaki tanım uygulamalarının karşılaştırılmasıdır.

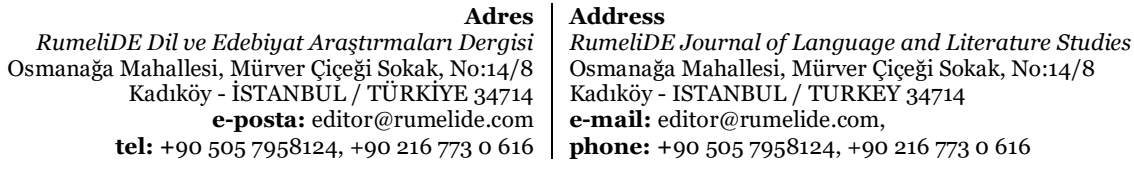


TS'de İngilizceden ödünçlenen sözlükbirimlerin tanımlarının İngilizce sözlüklerdeki tanımlarla karşılaştırılarak tanım yöntemleri bakımından incelenebilmesi için en uygun sözlüğün bağlam merkezli ve derlem tabanlı bir sözlük olan Wordnet olduğu düşüncesindeyiz. Bu bağlamda çalışmamızda yer alan sözlükbirimlerin İngilizcedeki tanımları, Wordnet'in açı erişimli ağ sayfası üzerinden elde edilmiştir. Orijinal yazımı ile TS'de yer alan sözlükbirimlere örnek olarak; advertorial, flamingo ve origami sözlükbirimleri örnek verilebilir. Çalışmada ilk olarak, bu sözlükbirimlerin tanım yöntemleri üzerinde duracağız.

\section{Türkçede yazımı değişmemiş İngilizceden alıntı sözlükbirimlerin tanımlarının incelenmesi}

TS’nin 11. baskısında, İng. etiketiyle yer alan alıntı sözlükbirimlerden yazımı değişmemiş 204 sözlükbirim şunlardır:

Tablo 1. TS’nin 11. baskısında, İng. etiketiyle yer alan alıntı sözlükbirimlerden yazımı değişmemiş 204 sözlükbirim

\begin{tabular}{|c|c|c|c|}
\hline \multicolumn{4}{|c|}{ Yazımı Değişmeyen Sözlükbirimler 1} \\
\hline $\begin{array}{l}\text { ace } \\
\text { advertorial } \\
\text { anchorman } \\
\text { antidumping } \\
\text { april } \\
\text { azonal } \\
\text { background } \\
\text { badminton } \\
\text { bar II } \\
\text { basket } \\
\text { benchmarking bk. Bilgileşim } \\
\text { bestseller bk. Çoksatar } \\
\text { billboard bk. Duyurumluk } \\
\text { blender bk. Karıştırıcı } \\
\text { boarding card bk. uçuş kartı } \\
\text { bodyguard bk. Koruma. } \\
\text { bold bk. Koyu } \\
\text { broker bk. Borsa simsarı } \\
\text { cash card bk. Nakit kartı } \\
\text { casting bk. Oyuncu kadrosu } \\
\text { catering bk. Yemek hizmeti } \\
\text { center bk. Merkez } \\
\text { change bk. Para değişimi } \\
\text { charter bk. Dolmuş uçak } \\
\text { chat bk. Sanal sohbet } \\
\text { check-in bk. Giriş işlemi } \\
\text { check-out bk. Çıkş işlemi } \\
\text { check-point bk. Denetim noktası } \\
\text { check-up bk. Tam bakım } \\
\text { chip card bk. Varlık kartı } \\
\text { clearing bk. Takas } \\
\text { compact disc bk. Yoğun disk }\end{array}$ & $\begin{array}{l}\text { dealer bk. Satım } \\
\text { dealing bk. Satım } \\
\text { defroster bk. Buz } \\
\text { demo } \\
\text { denim } \\
\text { designer bk. Tase } \\
\text { developer bk. Ylk } \\
\text { dimmer bk. Reos } \\
\text { dribbling bk. Top } \\
\text { dumping bk. Düs } \\
\text { elk } \\
\text { e-mail bk. Elektr } \\
\text { eurobond bk. Av } \\
\text { factor bk. Alacak } \\
\text { factoring bk. Alac } \\
\text { fair play bk. Dür } \\
\text { fan } \\
\text { fast break bk. Hır } \\
\text { fast food bk. Haz } \\
\text { faul } \\
\text { final-four bk. Dö } \\
\text { first lady bk. Baş } \\
\text { first-class bk. Bir } \\
\text { fit II } \\
\text { fitness } \\
\text { flamingo } \\
\text { flashback bk. Geı } \\
\text { flit } \\
\text { folk } \\
\text { font I } \\
\text { fork-lift } \\
\text { formika }\end{array}$ & $\begin{array}{l}\text { çözer } \\
\text { rımcı } \\
\text { amaç } \\
\text { a } \\
\text { sürme } \\
\text { ürü } \\
\text { onik posta } \\
\text { ovil } \\
\text { andırıcı } \\
\text { aklandırma } \\
\text { ist oyun } \\
\text { lı hücum dönüs } \\
\text { r yemek } \\
\text { tlü final } \\
\text { ayan } \\
\text { nci sınıf }\end{array}$ & $\begin{array}{l}\text { gag bk. gülüt } \\
\text { gazebo } \\
\text { guard } \\
\text { habitat } \\
\text { hacker bk. bilgsayar korsanı } \\
\text { half-time } \\
\text { handout bk. el notu } \\
\text { handsfree bk. dokunmasız } \\
\text { happy hour bk. indirim saatleri } \\
\text { hat trick bk üçleme } \\
\text { hedging bk koruma } \\
\text { high-tech bk yüksek teknoloji } \\
\text { hit } \\
\text { holding } \\
\text { ice-tea } \\
\text { iguana } \\
\text { in-line skate bk. kaykaç } \\
\text { instant coffee bk. hazır kahve } \\
\text { intern bk. ön hekim } \\
\text { internet bk. genel ağ } \\
\text { internship bk. ön hekimlik } \\
\text { intranet bk. yerel ağ } \\
\text { jam-session bk. toplu caz } \\
\text { jersey } \\
\text { jet ski bk. su kızağı } \\
\text { jet-lag bk. jet yorgunluğu } \\
\text { jogging bk. doğa yürüyüşü } \\
\text { joy-stick bk. kumanda kolu } \\
\text { kamikaze } \\
\text { langur } \\
\text { laptop bk. dizüstü } \\
\text { leasing }\end{array}$ \\
\hline $\begin{array}{r}\text { RumeliDE Dil ve Edeb } \\
\text { Osmanağa Mahallesi, Mü } \\
\text { Kadıköy - İS } \\
\text { e-po } \\
\text { tel: }+905057\end{array}$ & $\begin{array}{r}\text { Adres } \\
\text { raștirmalar Dergisi } \\
\text { içeği Sokak, No:14/8 } \\
\text { JL/ TÜRKIYE } 34714 \\
\text { ditor@rumelide.com } \\
4,+90216773 \text { o } 616\end{array}$ & $\begin{array}{l}\text { Address } \\
\text { RumeliDE Jou } \\
\text { Osmanağa Ma } \\
\text { Kadıköy - IST } \\
\text { e-mail: editor } \\
\text { phone: }+905\end{array}$ & $\begin{array}{l}\text { nguage and Literature Studies } \\
\text { irver Cicceği Sokak, No:14/8 } \\
\text { 'URKYY } 34714 \\
\text { e.com, } \\
4,+90216773 \text { o } 616\end{array}$ \\
\hline
\end{tabular}




\begin{tabular}{|l|l|l|}
\hline condenser bk. Yoğuşturucu & free-lance bk. bağımsız & lift \\
dancing bk. Dans salonu & free-shop bk. gümrüksüz mağaza & lifting bk. gerdirme \\
dart bk. Oklama & fuel-oil bk. yağ yakıt & liger \\
deadline bk. Süre sonu & full-time bk. tam gün & light \\
\hline
\end{tabular}

\begin{tabular}{|c|c|c|}
\hline \multicolumn{3}{|c|}{ Yazımı Değişmeyen Sözlükbirimler 2} \\
\hline $\begin{array}{l}\text { link II (İlişim) } \\
\text { lipostructure } \\
\text { liposuction } \\
\text { loader bk. yükler } \\
\text { logo bk. imlek } \\
\text { long-play bk. uzunçalar } \\
\text { market } \\
\text { market maker bk. piyasa kurucu } \\
\text { marketing bk. pazarlama } \\
\text { martin } \\
\text { master } \\
\text { megastar bk. başyıldız } \\
\text { megastore bk. büyük mağaza } \\
\text { mink } \\
\text { mobber bk. bezdirici } \\
\text { mobbing bk. bezdiri } \\
\text { morina } \\
\text { mortgage bk. tutulu satış } \\
\text { mouse bk. fare } \\
\text { nickname bk. takma ad } \\
\text { nod } 1 \text {. bk yumru } 2 . \text { bk. düğüm } \\
\text { no-frost bk. karlanmaz } \\
\text { non-stop bk. duraksız } \\
\text { notebook bk. dizüstü } \\
\text { off-line bk. Çevrim dışı } \\
\text { off-road bk. arazi yarışı } \\
\text { off-shore bk. kıyı bankacılığı } \\
\text { ombudsman } \\
\text { on-line bk. çevrim içi } \\
\text { origami } \\
\text { orion } \\
\text { outlet center } \\
\text { pacemaker bk. irtilkeç } \\
\text { pagan } \\
\text { pagoda } \\
\text { papaya }\end{array}$ & $\begin{array}{l}\text { part-time bk. yarım gün } \\
\text { peeling bk. soyum } \\
\text { pipe-line bk. boru hattı } \\
\text { plaster } \\
\text { playback bk. söylemseme } \\
\text { playmaker bk. oyun kurucu } \\
\text { play-off bk. üst küme } \\
\text { polo } \\
\text { portal } \\
\text { prime time bk. altın saatler } \\
\text { print } \\
\text { printer bk. yazıcı } \\
\text { puzzle bk. yapboz } \\
\text { radar } \\
\text { rafting bk. sal yarışı } \\
\text { rating bk. değerlendirme } \\
\text { ring } \\
\text { roaming bk. dolaşım ortaklığı } \\
\text { rodeo } \\
\text { salsa } \\
\text { sanskrit } \\
\text { satsuma } \\
\text { scoreboard bk. sayı göstergesi } \\
\text { self-service bk. seçal } \\
\text { server bk. sunucu } \\
\text { set II } \\
\text { single bk. tekli } \\
\text { ski } \\
\text { skink } \\
\text { slip I } \\
\text { snack-bar bk. atıştırma yeri } \\
\text { sponsor } \\
\text { sprint } \\
\text { sprinter } \\
\text { stand-by bk. destek } \\
\text { star }\end{array}$ & $\begin{array}{l}\text { start } \\
\text { sten I } \\
\text { step II } \\
\text { sticker bk. çıkartma } \\
\text { strectching } \\
\text { süpermarket } \\
\text { süperstar tangram } \\
\text { teenage bk. ergenlik } \\
\text { teenager bk. ergen } \\
\text { test } \\
\text { think-thank bk. beyin takımı } \\
\text { timing bk. zamanlama } \\
\text { toner } \\
\text { topless } \\
\text { trade center bk. ticaret merkezi } \\
\text { transporter bk. yükçeker } \\
\text { trekking bk. doğa yürüyüşü } \\
\text { trend bk. eğilim } \\
\text { tubeless bk. içsiz } \\
\text { vertigo } \\
\text { video } \\
\text { yen II } \\
\text { zapping bk. geçgeç }\end{array}$ \\
\hline
\end{tabular}

Yazımı değişmeyen 204 sözcükten advertorial, flamingo, origami sözlükbirimlerinin tanımlarını inceleyeceğiz.

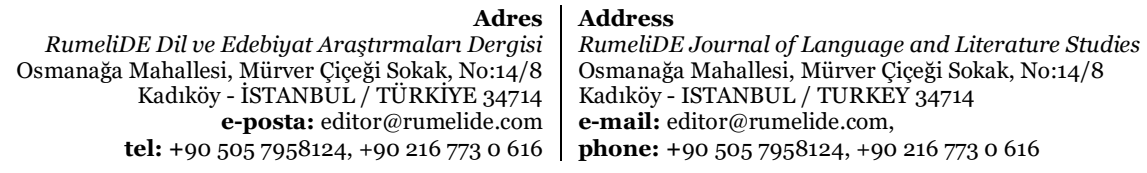


Advertorial sözlükbiriminin TS'deki tanımında sözlük kullanıcısı, tantıcı reklam sözlükbirimine gönderilmiştir. Tanıtıcı reklam sözlükbiriminin tanımı ise şu şekilde yapılmıştır:

tanıtıcı reklam: isim. "Tanıtılacak ürünün kullanımını ve etkilerini değişik ögeler yardımıyla ayrıntılı olarak haber biçiminde anlatan reklam"

Sözcüğün tanımı incelendiğinde, sıfat fiille yapılmış olan niteleyici bir yan cümle ve yan cümleden hemen sonra sözlükbirim ile üst-alt anlam ilişkisi kurarak üst anlam bildiren ad türündeki reklam sözcüğü kullanılmıştır. Bu sayede sözlükbirimin genel anlamda reklam kavramından hangi açılardan ayrıldığı yan cümle ile belirtilmiştir. Tanıma göre tanıtıcı reklamın reklamdan farkı, tanıtılacak ürünün kullanımını ve etkilerini değişik ögeler yardımıyla ayrıntılı olarak haber biçiminde anlatan reklam olmasıdır. Tanıma göre üst kavram-alt kavram ilişkisini sağlayan unsur, tanıtıcı reklamın biçimsel olarak haber biçiminde olmasıdır. Dolayısıyla sözlükbirimin, reklam üst kavramından ayrılan yönleri ayrrt edici özellik olarak verilmiş ve analitik yönteme başvurulmuştur.

Sözcüğün İngilizcedeki tanımı ise şu şekildedir:

advertorial: Noun. "An advertisement that is written and presented in the style of an editorial or journalistic report"

İngilizce tanımda da üst kavram alt kavram ilişkisi ve niteleyici yan cümle yardımıyla tanım yoluna gidilmiştir. Advertisement sözcügüule üst kavram verilirken that bağlacından sonra verilen yan cümle ile yine sözcügün gazetecilik raporu niteliğinde olması ve yazılma ve sunuş aşamaları ile kitlelere ulaştığı vurgulanmıştır. That bağlacından sonra üst kavramın ayırt edici özellikleri sıralanarak analitik tanım yöntemi uygulanmıştır. TS'deki tanımda tantılacak ürün üzerinden tanım oluşturulurken, WORDNET’in tanımında bu unsur üzerinde durulmadan advertisement "reklam" üst kavramı nitelenmiştir.

TS'de flamingo sözlükbiriminin tanımı şu şekildedir:

flamingo: isim, hayvan bilimi, (l ince okunur), İngilizce flamingo. "Leyleksilerden, tüyleri beyaz, pembe, kanatlarının ucu kara, eti yenir bir kuş, Flaman kuşu (Phoenicopterus ruber)”

Sözcük tanımlanırken analitik tanım yöntemi kullanılmıştır. Analitik tanım, özellikle hayvan türlerinin tanımlanmasında kullanılır ve hayvan bilimindeki alt-üst kavram ilişkisine dayanır. Bu tür tanımlarda +si ekiyle hayvan bilimi bakımından üst aileye ait grup belirtilir. Sözcügün tanımında leyleksilerden ifadesiyle bu üst grup belirtilmiştir. Ardından sıfatlarla niteleyici özellikler verildikten sonra sözlükbirimin üst kavramı olan kuş adı verilerek flamingonun tür olarak kuş olduğu vurgulanmıştır. Diğer hayvan adlarında da olduğu gibi sözcüğün Flaman kuşu biçiminde gönderildiği bir diğer sözlükbirim verilmiş ve son olarak da sözlükbirimin bilimsel-Latince adı belirtilmiştir. Flaman kuşu maddesinde ise sözlük kullanıcısı doğrudan flamingo maddesine gönderilerek, çapraz gönderim (crossreference) uygulanmıştır.

WORDNET’te sözcük şu şekilde tanımlanmıştır:

flamingo: Noun. "Large pink to scarlet web-footed wading bird with down-bent bill; inhabits brackish lakes"

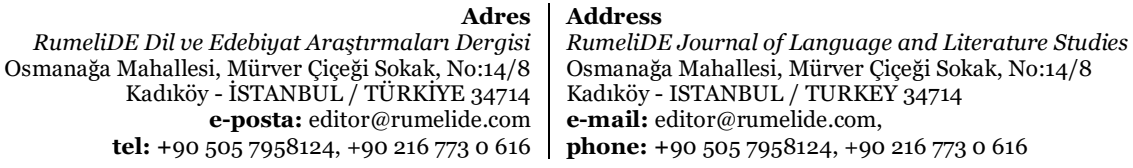


Sözcüğün İngilizce tanımında da bird "kuş" üst anlamının niteleyicilerle verildiği görülür. Sözlükbirim, kuş üst kavramı üzerinden, ayaklarının rengi ve şekli, gagasının biçimi, yürümesi gibi ayırt edici özellikleri verilerek tanımlanmış ve analitik tanım yapılmıştır. Buna ek olarak da inhabits brackish lakes "tuzlu (acı) göllerin çevresinde yaşarlar" şeklinde flamingoların habitatlarına dair ek bir bilgi de verilerek analitik tanımla birlikte sık kullanılan tipikleştirmeye başvurulmuştur.

Origami sözlükbiriminin tanımının TS'deki görünümü şu şekildedir:

origami: isim, İngilizce, origami. "Genellikle kare kâğıt parçalarını kesmeden ve yapıştırıcı kullanmadan sadece katlayıp çeşitli canlı ve cansız figürler oluşturularak yapılan kâğıt katlama sanatı”

Tanımda, katlama sanatı ifadesi üst kavram olarak verilerek, yapımında kare biçimindeki kâğıtların kullanılması ve nasıl yapıldığı yönünden ayırt edici özellikleri verilerek, özelde kâğıt katlama sanatı olduğu vurgulanmış ve analitik yöntem uygulanmıştır. TS'de analitik yöntem uygulanan tanımlarda sık karşılaştığımız biçimde “Genellikle...” ifadesi kullanılmış ve yardımcı unsur olarak tipikleştirmeye başvurulmuştur.

Sözcüğün İngilizcedeki tanımı ise şu şekildedir:

origami: Noun. "the Japanese art of folding paper into shapes representing objects (e.g., flowers or birds"

Tanımda, katlama sanatı üst kavramı ile kavramsal çerçeve çizilmiş ve Japonlara ait olması, kâğıtlarla yapılması, çiçek, kuş gibi şekillere benzetilmesi ayırt edici özellikleri verilerek analitik yönteme başvurulmuştur. Analitik yöntem içerisinde sık kullanılan yardımcı ögelerden olan örneklendirme ile tanım desteklenmiştir.

3. bölümde Türkçede yazımı değişen sözlükbirimlerden seçtiğimiz üç örneklemi inceleyerek özelliklerini belirteceğiz.

\section{Türkçede yazımı değişmiş sözlükbirimlerin tanımlarının incelenmesi}

TS’nin 11. baskısında İng. etiketli ve yazımı değişmiş 313 sözlükbirim bulunmaktadır:

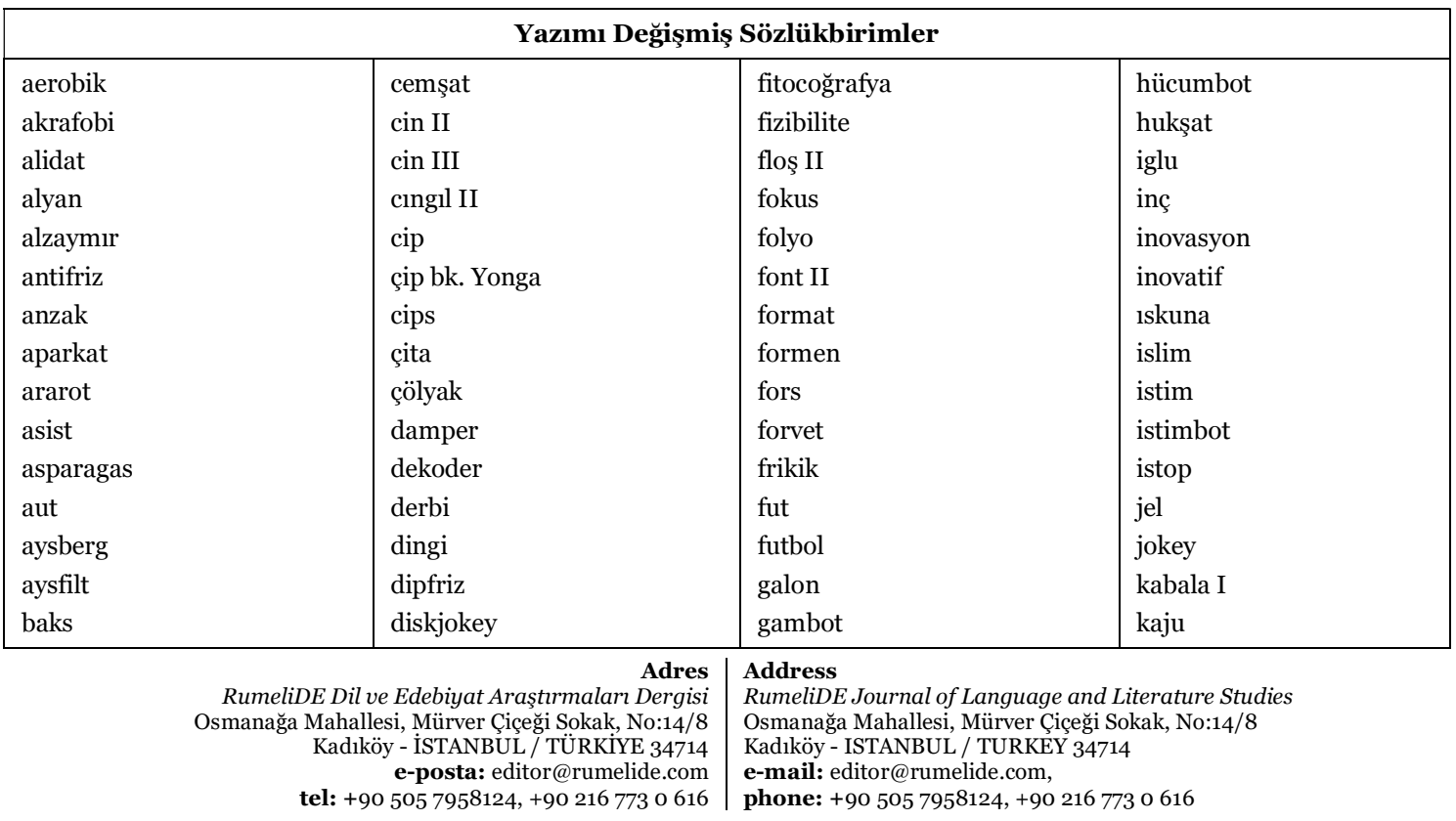


166 / RumeliDE Journal of Language and Literature Studies 2021.24 (September)

Definition methods of lexemes borrowed from English in Turkish Dictionary / M. S. Kumanlı (pp. 158-173)

\begin{tabular}{|l|l|l|l|}
\hline barkod & disko & garantör & kariyer II \\
başhostes & dispeç & gardenparti & karpit \\
basketball & diyafon & gey & kataklastik \\
baypas & dizayn & geyşa & kataklaz \\
bek II & dok & gol & kek \\
beyzbol & doping & golfstrim & kenter \\
bitnik & dorse & grafiti & kep \\
blöf II & dreç & gravite & ketçap \\
blucin & dretnot & greyder & kik \\
bot I & egzoz & greyfurt & klinker \\
bovling & ekru & grogi & klip \\
boyler & entertip & groston & klon \\
braket & ereksiyon & haf & koç II \\
briç & faks & handikap & kok \\
brifing & faril & hemafrodit & kokimbit \\
brik II & fayrap & hentbol & kokpit \\
brovning & feribot & hiperaktif & kokteyl \\
bumerang & fiberglas & hipermarket & kola II \\
çarliston & fikstür & hippi & kompost \\
caz & finiş & hobi & kontak lens \\
cazbant & fissür & hokey & \\
çek & fit III & hol & \\
& & holigan & hostes \\
& & & \\
\hline
\end{tabular}

\begin{tabular}{|c|c|c|c|c|}
\hline \multicolumn{5}{|c|}{ Yazımı Değişmiş Sözlükbirimler } \\
\hline korner & net II & rami & slap & trampet \\
\hline kort & nevton & raunt & slayt & trençkot \\
\hline koşin & obsesif & redoks & smaç & treyler \\
\hline krank & obsesyon & reeksport & sör II & triboloji \\
\hline kravl & ofsayt & reglan & sörf & trol \\
\hline kros & ofset & relaks & şort & tvist \\
\hline kurya & ordinat & remiks & şov & urbanizm \\
\hline lastikotin & oryantiring & rom & şovmen & uskur \\
\hline legorn & oşinografi & rot & spektrum & uskuru \\
\hline leydi & östrojen & röveşata & spor toto & vat \\
\hline limitet & otodrag & röyalti & sprey & videobant \\
\hline linç & otofokus & ruf & stant & videokaset \\
\hline lipozom & otomotiv & rupi & stepne & videoteyp \\
\hline lort & overlok & şaft & sterlin & vinç \\
\hline makarena & panikatak & sandviç & steyşın & vinter \\
\hline mayın & paunt & santrfor & stoper & viski \\
\hline medya & payreks & santrhaf & streç & voleybol \\
\hline mekatronik & pedofil & şarpi & stres & yat II \\
\hline metroseksüel & pedofili & şekel & striptiz & zombi \\
\hline mikrofiş & penaltı & seksi & şut & zum \\
\hline mikser & peni & şelf & tabanvay & \\
\hline milenyum & pik I & seloteyp & $\operatorname{taç~II~}$ & \\
\hline minorka & pik IV & sensör & taret & \\
\hline mis II & pikap & sent & tayfun & \\
\hline misis & piling & şerif II & tayt & \\
\hline
\end{tabular}

\section{Adres Address}

RumeliDE Dil ve Edebiyat Araşttrmaları Dergisi $\quad$ RumeliDE Journal of Language and Literature Studies Osmanağa Mahallesi, Mürver Çiçeği Sokak, No:14/8 Osmanağa Mahallesi, Mürver Çiçeği Sokak, No:14/8 Kadıköy - İSTANBUL / TÜRKIYY 34714 Kadıköy - ISTANBUL / TURKEY 34714

e-posta: editor@rumelide.com $\quad$ e-mail: editor@rumelide.com,

tel: +90 505 7958124, +90 216773 o 616 phone: +90 505 7958124, +90 2167730616 


\begin{tabular}{|l|l|l|l|l|}
\hline miting & pim & şerpa & tekila \\
mopet & pinpon II & seter & terilen \\
motokros & pirsing & şetlant & teyp \\
motorbot & pleybek & siborgiyum & tim \\
multimedya & proses & sif & tişört \\
müzikhol & puanter & şilin & tolkşov \\
nafta & puvar & şnav & tomahavk \\
nakavt & radyolink & skavut & tork \\
nanobakteri & ragbi & skeç & torpido bot & \\
nanoteknoloji & rakun & tost & \\
nanoteknolojik & ralli & skor & toto II & \\
& & & \\
\hline
\end{tabular}

Tablo 2. TS’nin 11. baskısında, İng. etiketiyle yer alan alıntı sözlükbirimlerden yazımı değişmiş 313 sözlükbirim

Türkçeye giren yabancı alıntıların çoğunda olduğu gibi İngilizce alıntılarda da yaygın biçimde ses değişimleri görülmüştür (Karaca, 2012: 2088). Türkçeye girişi daha eski dönemlerde gerçekleşen ve Türkçede yazımı değişen sözlükbirimlerden ise dispeç, dingi ve entertip sözlükbirimlerinin tanımlarını inceleyeceğiz. Dispeç sözlükbirimi TS'de şu şekilde tanımlanmıştır:

\section{dispeç: İngilizce Dispatch.}

1. isim, denizcilik Bir ortak avaryada deniz kazasından sonra gemi, yük ve navlunla ilgili kimselerin uğradıkları zararların ve bunlar tarafından yapılan masrafların nasıl, kimler tarafından ve ne oranda karşılanacağını belirlemek için yapılan işlem.

2. isim Deniz sigortası dilinde, ilgili tarafların ortak avaryada kendilerine düssen yükümlülükleri, paylarının önemi ölçüsünde ayrıntılı olarak belirten belge.

Sözcügün TS'de verilen anlamı özelleşen bir anlam olduğu için İngilizce sözlüklerde yer almamaktadır. Sözcüğün denizcilik terimi olarak özelleşip Türkçede kullanılmaya başlanıldığı düşünülebilir. Bu noktada, TS’ye sözlükbirim seçiminde sıklı temelli yaklaşılması gerektiği düşüncesindeyiz. Dispatch vs. gibi özel alanlara ait sözcüklerin daha çok özel alan sözlüklerinde sözlükbirim olarak yer alması daha uygun bir uygulama olarak gözükmektedir. Sözcüğün tanımları incelendiğinde 1 numaralı tanımın işlem üst kavramı verilmiş ve ne için yapıldığı üzerinden uzun bir betimleme yapılarak analitik yöntem uygulanmıştır. Tanımda kullanılan sözcükler incelendiğinde gemicilikle ilgili navlun sözcüğünün

İki numaralı tanımda ise sözlükbirimin deniz sigortası dilinde özel bir alana ait olduğu belirtilmiş ve sıfat fiil eki almış "belirten" sözcüğüyle yan cümle oluşturularak, belge sözcüğüyle oluşturulan alt anlamlılık ilişkisi bu yan cümle ile nitelenmiş ve analitik yöntem uygulanmıştır.

Tanımlarda verilen avarya (İtalyanca) ve navlun (Rumca) gibi sözcükler sözlükte sözlükbirim olarak da verilmesine rağmen sözlük kullanıcısı tarafından anlamının tahmin edilmesi zor olan ve Türkçeye başka dillerden giren sözcüklerdir. Bu gibi çeşitli jargon sözcüklerinin tanımlarda kullanılması, kodlama (encoding) açısından eksiklik oluşturduğu gibi kod çözme (decoding) aşamasında sözlük kullanıcısının işini zorlaştıracaktır. Dolayısıyla tanımda bu tip sözcükler kullanmak yerine sözlük kullanıcısının tanımı okurken anlayabileceği sözcüklere yer vermek genel bir sözlük olan TS için daha uygun bir yaklaşım olacaktır.

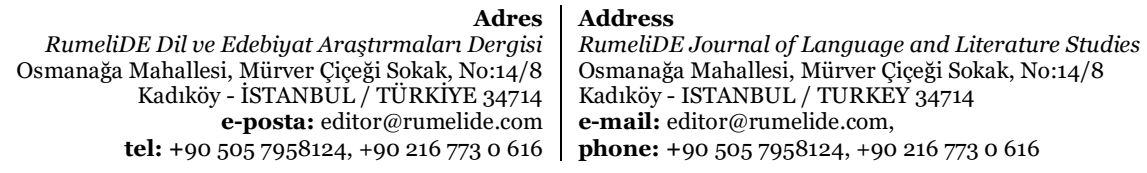


Yazımı Türkçede değişmiş olan bir diğer sözcük olan dingi sözlükbiriminin tanımı TS'de şu şekilde yapılmıştır:

dingi: isim, denizcilik, İngilizce dingy. "Bir çifte kürekli küçük patalya"

Tanımda, patalya sözcüğü üst kavram olarak belirlenmiş ve dinginin nasıl bir patalya olduğu sorusu, çifte kürek sayısı ve küçük olması ayırt edici özellikleriyle verilerek kısa bir analitik tanım yapılmıştır. Tanımlanan sözlükbirimin denizcilik terimi olması dolayısıyla tanımda kullanılan patalya sözcüğü kod çözme aşamasında sözlük kullanıcısının tekrar sözlüğe başvurmasına neden olacaktır.

Dingy sözcüğü İngilizce sözlüklerde dirty “kirli” anlamıyla sıfat olarak yer alırken TS'deki denizciliğe ait bir ad olan patalya anlamı, WORDNET veri tabanında bulunmamaktadır. Dispeç sözlükbiriminde olduğu gibi dingi sözlükbirimi de TS'den daha çok denizcilik terimlerine ait özel alan sözlüklerinde yer alması daha uygun olacak bir sözcüktür. Genel sözlüklerde yer alan bu tip kullanım alanı sözlükbirimler tanımlanırken tanıklamaya başvurulması sözlük kullanıcısının kod çözme sürecinde işini kolaylaştıracaktır. Dispeç ve dingi sözlükbirimlerinin tanımlarında ise herhangi bir tanıklamaya başvurulmamıştır.

Alıntı sözcüklerden entertip sözlükbiriminin TS'deki tanımı şu şekildedir:

entertip: isim, İngilizce intertype. "Basımcllıta harfleri satır olarak dizen ve döken dizgi makinesi"

Tanımda dizen ve döken sıfat fiil yapılarıyla yan cümleler dizgi makinesi üst kavramına bağlanmış ve üst kavramın nitelikleri verilerek analitik yöntem uygulanmıştır. Tanımın ilk sözcüğü olan basumcllkta ifadesiyle sözlükbirimin özel alana ait bir ad olduğu belirtilmiştir. Sözcük Türkçeye, özel bir dizgi makinesi markası aracılığıla geçmiştir.

Sözlükbirimin İngilizce biçimi olan intertype sözcüğü WORDNET’te yer almamaktadır. Bu durum, sözcüğün Türkçeye matbaacılık alanından geçen bir sözcük olması dolayısıyla alındığını göstermektedir ancak ölçünlü Türkçede kullanımı oldukça düşük olması ve tanımda herhangi bir tanıklamaya başvurulmaması sözlükbilim açısından sorunlu bir durumdur.

Çalışmamızın bu bölümünde TS'de yer alan ancak İngilizcede kullanılmayan sözlükbirimlerin tanımları üzerinde duracağız.

\section{TS'de sözlükbirim olarak yer alıp İngilizce sözlüklerdeki tanımlarında farklı anlamların verildiği sözcüklerin tanımlarının incelenmesi}

TS'de alıntı sözlükbirim olarak yer almasına rağmen İngilizce sözlüklerde TS'de verilen anlamının bulunmadığı sözlükbirimler de mevcuttur. Faril (farl), haf (half), overlok (overlock) sözlükbirimleri TS'deki bu türden sözcüklerdir.

Söz konusu sözlükbirimlerin İngilizce sözlüklerde farklı anlamlarla yer almasının sebepleri şu şekilde değerlendirilebilir:

a) TS'deki sözlükbirimle İngilizcedeki sözlükbirimin kökenlerinin farklı olması,

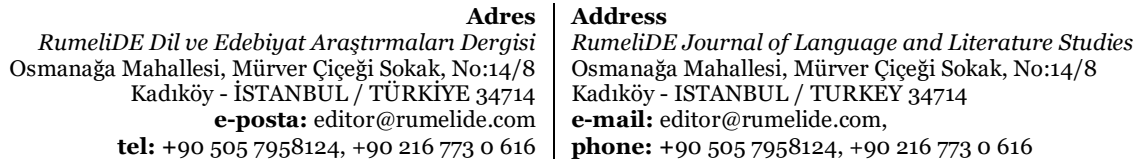


b) TS’de bulunan sözlükbirimin kökeni ile İngilizcedeki sözlükbirimin kökenleri farklı eşadlı sözlükbirimler olması,

c) Sözlükbirimin Türkçeye başka bir köprü dilden geçmiş olması.

Bu sözcüklerden WORDNET veritabanında sözlükbirim olarak yer almayanlarını da tanım yöntemleri ve tanımda verilen farklı anlamları bakımından inceleyebilmek amacıyla Merriam-Webster (MW) Sözlüğünün ağ sayfasında bulunan tanımlarını esas alacağız.

Faril sözlükbirimi, TS'de şu şekilde tanımlanmıştır:

faril: isim, İngilizce farl. "Balık ağlarının alt ve üst yanlarına geçirilen keçi kılından yapılmış ip"

Tanımda ip sözcüğü üst kavram olarak belirlenmiş ve sözlükbirimin nasıl kullanıldığı ile hangi malzemeden yapıldı̆̆ı ayırt edici özellikleri verilerek analitik yöntem uygulanmıştır. İngilizce sözlüklerde sözcükle ilgili olarak border rope for furling a net yapısına rastlanır bu yapı Türkçedeki faril anlamında kullanılır. İngilizcede ise bu anlamı WORDNET’te de sözlükbirim olarak yer alan furl “yuvarlayarak silindir hâline getir-” eylemi karşılamaktadır. Hasan Eren de faril sözcüğünü aynı şekilde tanımlamış ve sözcüğün kökeninin bilinmediğini belirtmiştir. Kubbealtı Lugati’nde de sözcük, "kökü belli değil” olarak işaretlenmiştir. (Eren, 1999: 143; http://lugatim.com/s/faril). Bu veriler göz önünde bulundurulduğunda TS’nin faril tanımında kullandığı İngilizce etiketinin tanıklanamadığı için değiştirilmesi uygun olacaktır.

Farl sözcügünün tanımı WORDNET veritabanında bulunmazken, sözlükbirimin $M W$ daki tanımı ise şu şekilde yapılmıştır:

farl: "a small thin triangular cake or biscuit made especially with oatmeal or wheat flour"

Sözcüğün tanımında TS'de yer alan anlamdan farklı olarak İskoçya’ya özgü bir yiyeceğin tanımı yapılmıştır. Kek ve bisküvi üst kavramları ile kavramsal çerçeve çizilerek sözlükbirimin ayırt edici özellikleri yulaf ezmesi veya buğday unu ile yapılması ve küçük, ince üçgen biçiminde olması ile betimlenmiş ve analitik yönteme başvurulmuştur.

TS'de haf sözlükbiriminin tanımı ise şu şekilde yapılmıştır:

haf: isim, spor, İngilizce half. "Hücumcularla savunucular arasında yer alan oyuncu"

Tanımda haf sözlükbirimi ait olduğu oyuncu üst kavramının kendisi ile birlikte alt üyeleri olan hücumcu ve savunucu ögeleri ile olan ilişkisi üzerinden betimlenmiş ve sentez yöntemi uygulanmıştır.

Haf sözcüğünün WORDNET veri tabanındaki tanımında ise aşağıda vereceğimiz temel anlam tanımlanmış ve diğer yan anlamlar onunla ilişkili olarak sıralanmıştır ancak spor terimi olarak anlamına değinilmemiştir:

haf: Noun. "one of two equal parts of a divisible whole "half a loaf"; "half an hour; a century and one half"

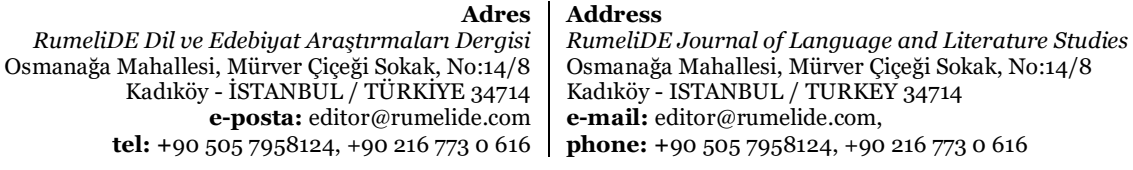


Tanımda, sözlükbirimin "bölünebilir bir bütünün iki eşit parçasından biri” olduğu belirtilerek parça bütün ilişkisi taşıyan meronimik (meronymy) tanıma başvurulmuştur.

Sözcüğün İngilizce kökenli orijinalinden eksiltme yoluyla Türkiye Türkçesine half-back $>$ haf biçiminde eksiltiye uğrayarak geçtiğini düşünmekteyiz. Eksiltili yapılar, Türkiye Türkçesinde sözlükselleşme (lexicalization) sürecinin önemli unsurlarıdır. Bu sözlükbirimde bir sözcügü̆n düşmesiyle oluşan eksiltili yapıdan sözlükselleşme söz konusudur. Ancak Türkiye Türkçesindeki sözlükselleşme bununla sınırlı değildir:

Eksiltili yapıdan sözlükselleşmenin yalnızca bir sözcüğün düşmesi ile açıklanamayacağını; anlık oluşum (nonce formation) ile başlayan kurumsallaşma (institutionalization) ile süren, sözlükselleşme (lexicalization) ile sonuçlanan bir süreçte yeni bir yapıya ulaşan sözcüklerin artık bir dilbilgisi yapısında çıkıp sözlük değeri kazanmış öge hâline geldiğini belirtmeliyiz (Akalın, 2014, s. 17-18).

Bu bağlamda söz konusu sözlükbirimin kaynak dildeki biçiminin eksiltiye uğramamış biçiminin verilmesi, sözlüğü köken bakımından araştırma yapmak amacıyla kullanabilecek sözlük kullanıcılarının kod çözme (decoding) sürecinde işini kolaylaştıracaktır. Türkiye Türkçesindeki kullanım sıklığının düşük olmasına rağmen esk. biçiminde bir etiketin kullanılmamış olması da TS’nin etiketleme konusunda bir eksikliğidir.

Overlok sözlükbiriminin TS'deki tanımı ise şu şekilde yapılmıştır:

overlok: isim, İngilizce overlock. "Kumaş, halı, kilim vb.nin kenarına makine ile yapılan sıkı, zikzaklı dikiş"

Tanımda, dikiş üst kavramı verilerek, sözlükbirimin üst kavrama göre ayırt edici özellikleri nelerin kenarına yapıldığı ve yapımında makine kullanılması ile sıkı ve zikzakl olması açılarından betimlenerek analitik yönteme başvurulmuştur. Sözcüğün İngilizceden alınan bir sözcük olduğu İngilizce etiketiyle gösterilmiştir. Sözcüğün İngilizce aslı da overlock biçiminde işaretlenmiştir. Haf sözlükbiriminde olduğu gibi kodlama (encoding) sürecinde orijinal biçimlerin eksiltilmeden verilmesi etimolojik bilginin kaybolmaması ve tanımda işaretlenmesi bakımından önemli olduğu için bu overlock seam biçiminin tanımda kodlanması sözlükbilim ilkeleri bakımından daha uygun olacaktır.

Overlock sözlükbiriminin İngilizce sözlüklerde TS'deki anlamıyla yer almadığı ancak "overlok dikiş" anlamında overlock seam biçiminin kullanıldığı görülmektedir. Sözcüğün Türkçede overlock biçiminde sözlükselleştiği görülmektedir. İngilizcede overlok anlamında ise daha çok serging biçimi kullanılmaktadır.

Overlock sözlükbiriminin üçüncü anlamı TS'deki tanımla aynı anlamı taşımaktadır ve şu şekilde yapılmıştır:

overlock: "to overcast by machine"

Tanımda overlock sözlükbiriminin "makine ile dikmek" anlamına geldiği belirtilmiş ve dikmek üst kavramı makine ile yapılması açısından nitelenerek tek yönlü betimlemeye başvurulmuştur.

Serging sözlükbiriminin MW'daki tanımı ise şu şekilde yapılmıştır:

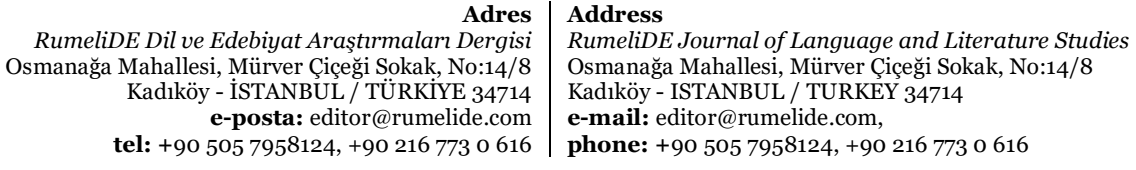


serging: "the process of overcasting the raw edges of a piece of fabric (such as a carpet) to prevent raveling"

Tanımda, “dikme işlemi süreci” üst kavram olarak belirlenmiş ve yırtılmayı önlemek için yapıldığı ile halı gibi kumaş parçalarına uygulandığ vurgulanmıştır. TS ve WORDNET’teki tanımda makine aracılı̆̆ıla yapıldığı ayrıca verilirken MW'daki tanımda sözlükbirimin bu ayırt edici özelliği göz ardı edilmiştir.

Çalışmamız kapsamında İng. etiketli alıntı sözlükbirimlerin tanımları TS, WORDNET ve MW üzerinden karşlaş̧tırmalı olarak incelenmiştir. Elde ettiğimiz bulgular ve öneriler ise sonuç bölümünde ifade edilmiştir.

\section{Sonuç}

TS’nin 11. baskısındaki İngilizce ödünçlemeler üzerine yaptığımız çalışma sonucunda elde ettiğimiz sonuçlar şunlardır:

Çalışmada, yeni ödünçlenen-yazımı değişmeyen sözlükbirimlerin daha çok son dönemde teknolojik gelişmeler ve bu gelişmelerin İngilizce aracılığıyla diğer kültürler üzerinde etkili olmasının bir sonucu olarak genellikle terim sözcükleri olduğu ve özellikle son dönemlerde teknik terimler üzerine birçok sözcüğün ödünçlendiği görülmektedir. Bir anlamda Osmanlı Türkçesinin son döneminde görülen ve Türkiye Türkçesinde de etkisini sürdüren Fransızcadan ödünçlemelerin yerini zamanla İngilizce terimler almıştır.

Yeni-yazımı değişmeyen sözlükbirimlerin birçoğunun tanımlanmasında karşılık olarak Türkçede üretilen sözcükler " $b k . x$ " biçiminde verilirken bazı ödünçlenmiş sözlük birimlerin Türkçede oldukça yerleşmiş ve yeni ve özel kavram alanları kazanmış olmalarından dolayı Türkçe karşılık üretilemediği görülmüştür. Örneğin; toner, süperstar, video, vertigo gibi sözlükbirimler sözlükte bu şekilde yer almıştır.

TS üzerinde alıntı sözlükbirimler üzerine hangi sözcüğün maddebaşı olarak belirleneceği konusunda farklı görüşlerin olduğu görülmektedir. Bu konuda, alıntı sözcüklerin Türkiye Türkçesinde Türkçe karşılıklarından farklı bir anlam alanı ve kullanım sahası kazanması durumunda TS'ye alınması gerektiği kanısındayız.

Çalışmamızda belirttiğimiz üzere bazı sözlükbirimler İngilizcede yaygın kullanıma sahip olmamasına ve çalışmamızda kullandığımız Wordnet veri tabanında bulunmamasına rağmen TS'de yer alması, bu sözcüklerin TS'de sözlükbirim olmasina gerek var mı? sorusunu beraberinde getirmektedir. Bu sorunun sözlükbilim açısından doğru şekilde cevaplanması için de TS'de bu sözcüklerin derlem tabanlı sıklık istatistiklerine bağlı olarak sözlükbirim olarak belirlenmesi gerekmektedir.

TS'de sözlükbirim olarak yer almasına rağmen İngilizce sözlüklerde Türkçedeki anlamı sıklıkla kullanılmayan sözcükler için TS'de bu sözcüklerin Türkiye Türkçesinde özel bir anlam alanı kazandığına dair ayrı bir etiketleme sistemi kullanılabilir. Türkçe sözlüklerdeki kuramsal sorunların genel anlamıyla sözlükbirim seçiminde derlem tabanlı bir anlayışa sahip olmamasından kaynaklandı̆̆ görülmektedir. Genel olarak Türkçe sözlükbirim seçiminde de görülen bu sorun alıntı sözcüklerin seçiminde de karşımıza çıkmaktadır.

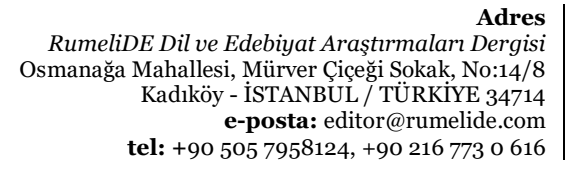

Adres
RumeliDE Dil ve Edebiyat Araştırmaları Dergisi
Osmanağa Mahallesi, Mürver Çiçĕi Sokak, No:14/8
Kadıköy - İSTANBUL / TÜRKIYY 34714
e-posta: editor@rumelide.com
tel: +90 505 7958124, +90 2167730616

Address

RumeliDE Journal of Language and Literature Studies

Osmanağa Mahallesi, Mürver Çiçeği Sokak, No:14/8

Kadıköy - ISTANBUL / TURKEY 34714

e-mail: editor@rumelide.com,

phone: +90 $5057958124,+902167730616$ 
TS'de yer alıp İngilizce sözlüklerde bulunmayan sözlükbirimlerin genel bir sözlük olan TS'de yer almasının ne derece doğru olduğu tartışmalıdır. Bu sözlükbirimlerin özel alan sözlüklerinde yer almasının daha doğru olabileceği düşünülebilir. TS'de İngilizcedeki asıl biçiminden eksiltili biçimde sözlükselleşmiş sözlükbirimlerin kaynak dildeki asıl biçimleri gösterilerek verilmesinin sözcüğün kaynağına dair kod çözme aşamasında sözlük kullanıcısına yardımcı olacağı düşüncesindeyiz.

Sözlük kullanıcıları kod çözme sürecinde sözlükbirimi anlamlandırırken ilişkili olduğu başka bir nesneye atfetme eğilimindedir (Gençer, Yavuzarslan, 2020: 402). Bu nedenle çalışmada ele aldığımız haf sözlükbiriminin sentez yöntemi ile tanımlanan tek sözlükbirim olması, futbol ile ilgili bir kavram olduğu için sahanın bölümleri açısından ele alınıp kodlanmasını kolaylaştırmış ve sözlükbilim ilkeleri bakımından uygun bir tanım yapılmıştır.

TS'de İngilizce sözlüklerden farkı anlamları ile yer alan sözlükbirimlerin Türkçede yazımı değişmiş sözlükbirimler olduğu görülmektedir. Bu nedenle, alıntı sözcüklerin dilde kullanım süresinin uzamasına bağlı olarak yazımında yerlileştirmeye gidilmesinin sözcüğün kullanımında anlam değişiminin bir göstergesi olduğu görülmektedir.

TS’nin 11. baskısındaki 517 adet İngilizceden alıntı sözlükbirimin tanımlanması üzerine yaptığımız araştırmada incelenen sözlükbirimlerden 204'ü Türkçede yazımı değişmeyen sözcüklerdir. Bu sözcüklerin 116'sında $b k$. "bakınız" etiketi ile göndermeye başvurulmuştur. Geriye kalan yazımı Türkçede değişmiş 313 sözlükbirimin tanımında ise gönderme yapılmamıştır. Çalışmada tanım yöntemlerini incelediğimiz 10 örnek sözlükbirimin 9'unun tanımında analitik tanım yöntemi kullanılmıştır. 1 sözlükbirimin tanımında ise sentez yöntemi kullanılmıştır.

TS'de bulunan sözlükbirimlerde kullanılan tanım yöntemleri üzerine yapılan son çalışmalarda en çok kullanılan yöntemlerin sırasıyla; eşanlamlısı ile tanımlama ve gönderme, analitik yöntem, tek yönlü betimleme ve sentez yöntemi olduğu belirlenmiştir (Kumanlı, 2021: 408). Bu açıdan TS'nin genel tanım eğiliminin İngilizceden alıntı sözlükbirimlerde de görüldüğü ifade edilebilir.

\section{Kaynakça}

Akalın, Ş. H. (2014). Türkçede Eksiltili Yapıdan Sözlükselleşme. Hacettepe Üniversitesi Edebiyat Fakültesi Dergisi. 31(2), 13-29.

Banguoğlu, T. (2000). Türkçenin Grameri (5. baskı). Ankara: Türk Dil Kurumu.

Buran, Ahmet (2001). Yabancı Diller Karşısında Türkçe. Türk Yurdu. 21(1), 162-163: 79.

Durmuş, O. (2004). Alıntı Kelimeler Bakımından Türkçe Sözlük. Erzurum Atatürk Üniversitesi Türkiyat Araştırmaları Enstitüsü Dergisi, 11(26), 1-21.

Eren, H. (1999). Türkçenin Etimolojik Sözlüğü. Ankara: Türk Dil Kurumu.

Ergene, O. (2014). Alıntı Sözcükler İçin Verilen Kaynak Dil ve Özgün Biçim Bilgileri Açısından Türkçe Sözlüklerin Karşılaştırılması. Turkish Studies, 9(3), 647-674.

Gençer, G. B. ve Yavuzarslan, P. (2020). Genel Sözlüklerde Tanım ve Tanımlama Yöntemleri. Modern Türklük Araştırmaları Dergisi, 17(3), 392-411.

Hartmann, R. R. K. (2001). Teaching and Researching Lexicography. Longman.

Karaca, V. İ. (2012). Türkiye Türkçesinde Alıntı Sözcüklerde Görülen Ses Olayları Üzerine Bir İnceleme. Turkish Studies, 7(4), 2059-2090.

Kubbealtı Lugati (t.y.). Erişim: 20.06.2021 tarihinde http://lugatim.com/ adresinden erişilmiş̧ir.

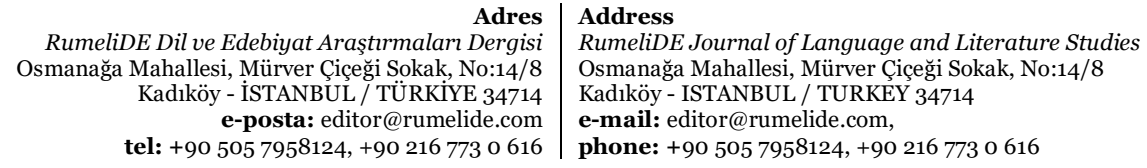


Kumanl, M. S. (2021). TDK Türkçe Sözlük’te “hlk.” Etiketli Sözcüklerin Tanımlanma Ölçütleri. Doktora Tezi. Hacettepe Üniversitesi, Ankara.

Merriam Webster. (t.y.). Erişim: 15.04.2021 tarihinde https://www.merriam-webster.com/ adresinden erişilmiştir.

Robinson, R. (1962). Definition. London: Oxford University Press.

Svensén, B. (2009). A handbook of lexicography: The theory and practice of dictionary-making (pp. 480-487). Cambridge: Cambridge University Press.

Türk Dil Kurumu. (2011). Türkçe Sözlük. Ankara: Türk Dil Kurumu.

Türk Dil Kurumu. (t.y.). Erişim: 17.06.2021 tarihinde www. sozluk.gov.tr adresinden erişilmiştir.

Wordnet. (t.y.). Erişim: 10.02.2020 tarihinde www. wordnetweb.princeton.edu adresinden erişilmiştir.

RumeliDE Dil ve Edebiyat Araştırmaları Dergisi Osmană̆a Mahallesi, Mürver Çiçeği Sokak, No:14/8 Kadıköy - ÍSTANBUL / TÜRKIYE 34714 e-posta: editor@rumelide.com tel: +90 $5057958124,+902167730616$
Address

RumeliDE Journal of Language and Literature Studies Osmanağa Mahallesi, Mürver Çiçeği Sokak, No:14/8

Kadıköy - ISTANBUL / TURKEY 34714

e-mail: editor@rumelide.com

phone: +90 $5057958124,+902167730616$ 